\title{
Do inequality, unemployment, and deterrence affect crime over the long run?
}

\author{
Mauro Costantini*1, Iris $\mathrm{Meco}^{1}$, and Antonio Paradiso ${ }^{2}$ \\ ${ }^{1}$ Department of Economics and Finance, Brunel University London, UK \\ ${ }^{2}$ Department of Economics, Ca' Foscari University, Italy
}

\begin{abstract}
This paper aims to investigate the long run relationship between crime, inequality, unemployment and deterrence using US state level data from 1978 to 2013. The novelty is to use nonstationary panels with a factor structure. The results show that: i) a crime theoretical model fits the long run relationship well; $i i$ ) income inequality and unemployment have a positive impact on crime, whereas that of deterrence is negative; iii) the effect of income inequality on crime is larger when inequality is measured on a wider population proportion; $i v$ ) property crime is generally highly sensitive to the deterrence effect of police.
\end{abstract}

Keywords: US Crime, deterrence, inequality, unemployment, panel cointegration, cross-section dependence.

JEL Codes: C33, E20, K40

*Corresponding author. E-mail address: mauro.costantini@brunel.ac.uk. Department of Economics and Finance, Brunel University London, Uxbridge, UB8 3PH, UK, Telephone: +44 (0)1895 267958, Fax: 00441895269770. 


\section{Introduction}

Crime is a phenomena linked to the growth of an economy, ${ }^{1}$ but it also depends on the developments of sub-national areas. Observing the growth dynamics of an economy may only partially help understand the trend of crime, ${ }^{2}$ and the study of the evolution of crime at sub-national level can enhance the understanding of the phenomena (see, for example, recent studies by Johnson and Raphael, 2012; Chintrakarn and Herzer, 2012; Blomquist and Westerlund, 2014; Neal, 2015).

Estimates of crime at sub-national level may be more consistently significant than those at national level due to a reduction in the aggregation bias, and data aggregated at national level tend to cancel out relevant differences in crime that feature different crosssection units (see Chiricos, 1987). Further, it is documented that crime tends to follow a trending pattern (see Narayan et al., 2010). In addition, the study of crime over the long run period is crucial since the implications of committing crime are long-lasting, and deterrence measures tend to impact on crime over a long run horizon (Nagin, 1998; Baker and Westelius, 2013). In this respect, the use of time series unit root and cointegration techniques for single-country analyses may be not particular suitable since cross-section variations are ignored. On the other hand, standard panel approaches do not consider unit root behaviour in crime, which may lead to spurious regressions. The use of nonstationary panels is therefore recommended. In particular, this paper applies macro-econometric panel data techniques based on a common factor structure to estimate the long run relationship between different types of crime, unemployment, inequality and deterrence activity in the US at state level over the period 1978-2013.

The use of a factor structure is motivated by the fact that the dynamic of crime at disaggregated level may have a strong comovement component, that is there may be common factors driving the evolution process of crime (see e.g. McDowall and Loftin, 2009; Blomquist and Westerlund, 2014). This seems to be the case for crime data in the US. In Figure 1, the estimated first principal component of the growth rate of the two main type

\footnotetext{
${ }^{1}$ Generally, an increase in GDP improves the well-being of citizens, reduces the unemployment rate and affects other economic factors which may have an impact on crime (see Malby and Davis, 2012).

${ }^{2}$ Levitt (2004) shows that the growth rate of the US economy over last years plays a marginal role in explaining the trend of crime.
} 
of crimes, property and violent crime, of the states grouped in the same region (Northeast, South, West, Midwest) is reported along with the aggregate crime growth pattern. ${ }^{3}$ It clearly emerges that the rates of crime across states tend to move together with the US aggregate crime growth rate. This suggests that the states under investigations are largely interconnected. Therefore, in this context, the use of an econometric methodology that accounts for cross-section dependence using factor models seems to be appropriate.

Our empirical analysis proceeds as follows. After applying the PANIC approach by Bai and $\mathrm{Ng}$ (2004) for testing unit root, the existence of cointegration is checked by the Durbin-Hausman type panel cointegration test developed by Westerlund (2008). Once cointegration is verified, a crime equation - which is derived from the theoretical approach by Edmark (2005) and Wu and Wu (2012) - is estimated using the continuously-updated (CUP) estimator developed by Bai and Kao (2006). The advantage of using the CUP estimator is that it addresses the issue of serial correlation and endogeneity. In estimating the crime equation, several measures of crime rates (property, violent, robbery, burglary, larceny and auto theft), inequality (top 10\% and top 5\% of income earners, and Gini index), and two measures of crime prevention (prison admissions per crime and state expenditure in police defense) are used.

This paper contributes to the empirical literature on crime in the US in a number of respects. First, to the best of our knowledge, this is the first paper to estimate the long run relationship between crime, unemployment, inequality, and deterrence in the US using nonstationary panels. This represents a further step in the analysis for crime in the US, since previous studies have only focused on crime and inequality (see Chintrakarn and Herzer, 2012; Neal, 2015). Second, this paper uses factor models to deal with cross-section dependence (see Blomquist and Westerlund, 2014; Birkel, 2014). Third, a recently developed estimator for nonstationary panels that control for endogeneity and serial correlation is

\footnotetext{
${ }^{3}$ The regional categorization follows the US Bureau classification. We are interested in understanding whether a common factor may lead to a comovement in the US states crime rates. One simple way of identifying this factor is to find a linear combination of crime rates in the specific US regions (i.e. Northeast, South, West, Midwest). The first principal component is calculated such that it accounts for the greatest possible variance in crime data. Therefore, the first component, denoted as $U_{1}$, is computed as a linear combination of constituent variables, $y_{1}, \ldots, y_{n}$, such as $U_{1}=\omega_{1} y_{1}+\ldots+\omega_{n} y_{n}$, where $w=\left[\omega_{1}, \ldots \omega_{n}\right]$ denotes the weights. For more details, see Joliffe (2002).
} 


\section{Property crime}

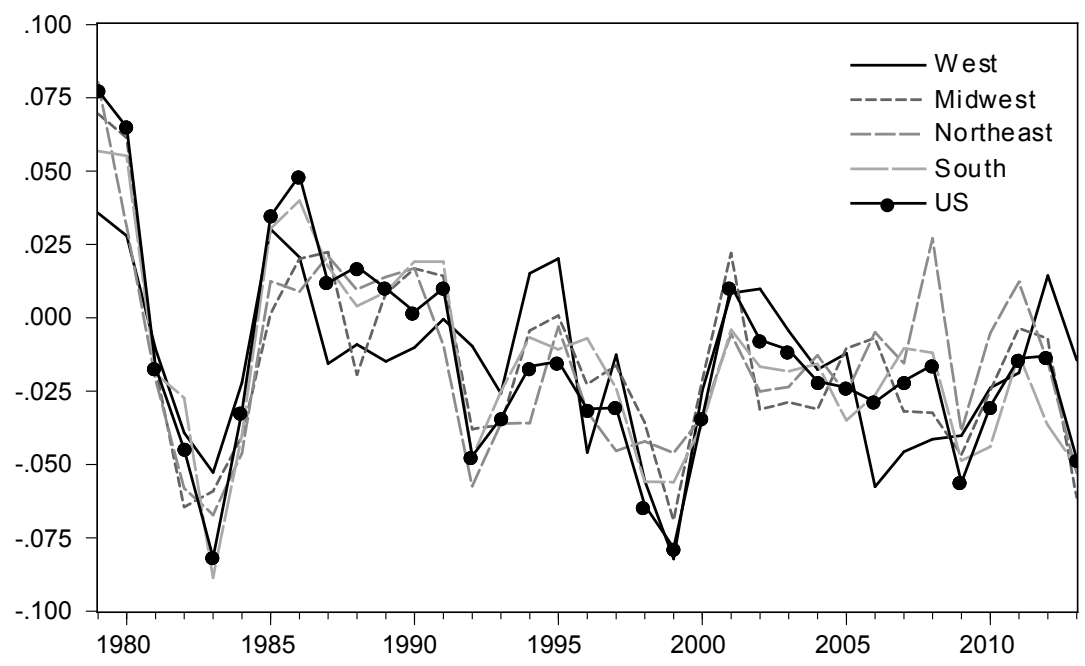

Violent crime

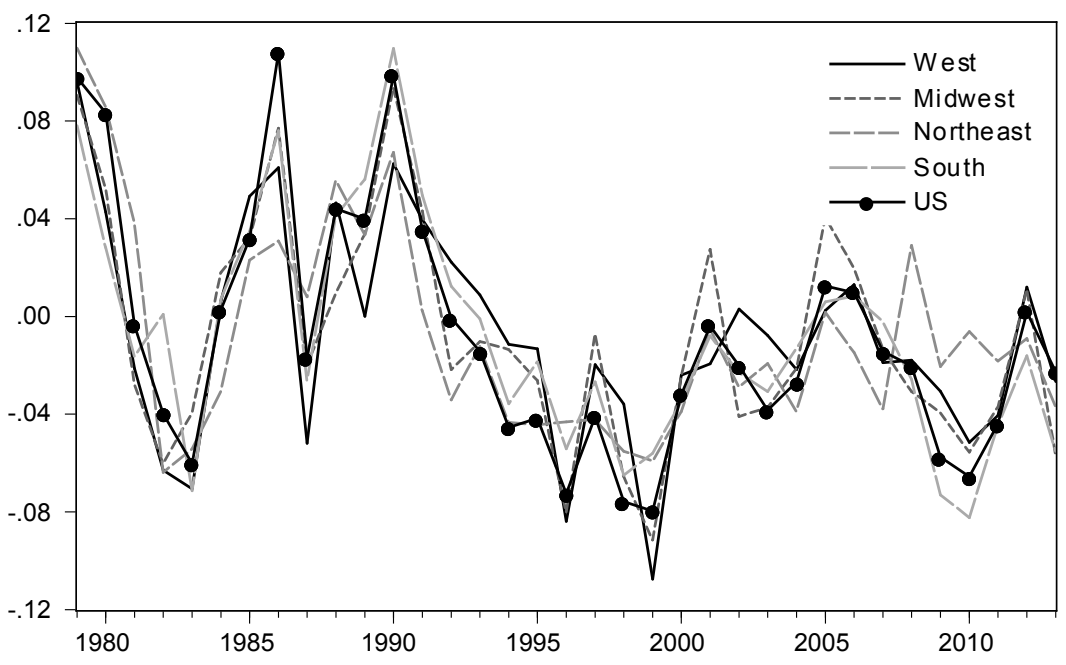

Figure 1: Estimated first principal component of the crime growth rates of various US states entering in the same regions (Northeast, South, West, Midwest) and aggregate crime growth pattern. 
used. Finally, a sensitivity analysis for crime using different measures of crime, deterrence and inequality is carried out.

The paper is organised as follows. The second section presents a literature review on previous crime studies. The third section illustrates the theoretical model of crime that represents the basis of our empirical analysis. The fourth section describes the data and the econometric methodology used. The fifth section discusses the empirical results. The sixth section draws conclusions.

\section{Literature review}

Over the last few decades, the wide variation in crime rates across regions, metropolitan areas, and cities has triggered a vast literature in criminology, sociology, and economics, with the aim to explain the determinants of crime. Inspired by the seminal works of Becker (1968) and Ehrlich (1973), several authors have examined the effect of changes in inequality, labor market conditions, and deterrence activity on changes in crime rates in the US.

In general, the relevance of a deterrence measure as a valid instrument to reduce crime has been documented in empirical studies. In particular, higher incarceration rates are associated with lower crime rates (Marvell and Moody, 1994; Levitt, 1996; Becsi, 1999; Doyle et al., 1999; Raphael and Winter-Ebmer, 2001; Vieraitis et al., 2007), ${ }^{4}$ and more intense police activities are accompanied by a reduction in crime (Kelly, 2000; Levitt, 2002; Lin, 2009). ${ }^{5}$ All the above studies use panel data at state level, with the exception of Kelly (2000) who focuses on cross-sectional data at county level. Further, those analyses conducted at state level mostly use fixed effect estimator, except Levitt (1996), Doyle et al. (1999), Levitt (2002), and Lin (2009) who apply instrumental variable approach in order to address potential endogeneity issues. Another important aspect of this literature is that some of the empirical results are obtained looking at the impact of differ-

\footnotetext{
${ }^{4}$ Spelman $(2006)$ concludes that a $10 \%$ increase in imprisonment rates produces on average a $2-4 \%$ decrease in crime rates.

${ }^{5}$ Nagin (2013) summarizes that "studies of police presence consistently find that putting more police officers on the street has a substantial deterrent effect on serious crime."Becsi (1999) and Doyle et al. (1999) are the exceptions in the literature since in their analysis police increases crime.
} 
ent measures of deterrence (see Levitt, 1996; Becsi, 1999; Doyle et al., 1999; Levitt, 2002). In this paper, we follow this literature and investigate the impact of different measures of deterrence on crime. However, unlike Levitt (1996, 2002), the issue of potential endogeneity in crime regressions is addressed using a suitable estimator for estimating crime over the long run.

As for the impact of unemployment rate and income inequality on crime, there is a general consensus that higher unemployment rates (Levitt, 1996; Doyle et al., 1999; Raphael and Winter-Ebmer, 2001; Gould et al., 2002) and larger income inequality (Kelly, 2000; Choe, 2008) increase crime. In particular, a positive and significant impact of unemployment on crime is found, regardless of the kind of crime used in the analysis. However, the magnitude of this impact is found to be different across crimes (see Levitt, 1996), which suggests the use of different types of crimes in empirical analyses, as this paper does. In studying the impact of income inequality on crime, Kelly (2000) and Choe (2008) use Gini index as a measure of inequality. However, different levels of income distribution may have a different impact on crime, as argued by Allen (1996). Therefore, inspired by Allen's (1996) argument, this paper uses diverse measures of inequality. ${ }^{6}$

All the previous studies mentioned above use cross-section or panel data techniques that seem to neglect the role that the long run period may play in understanding crime behaviour. As pointed out by Nagin (1998) and Baker and Westelius (2013), crime is by its nature a phenomena that has implications in the long run period since the effect of committing crime are long-lasting and measures of deterrence impact on crime over a long run horizon. One implication of this is that long run elasticity of crime rates with respect to socio-economic variables may be of different magnitude with respect to that of short run period. Therefore, the use of techniques which take these aspects into account seem to be more appropriate when seeking to understand criminal behaviour.

It is therefore unsurprising that the works by Chintrakarn and Herzer (2012) and Neal (2015) consider the long run period when estimating a crime equation at state level in the US. In particular, Chintrakarn and Herzer (2012) use panel cointegration techniques under

\footnotetext{
${ }^{6}$ In addition to top $10 \%$ and Gini inequality measures used in Chintrakarn and Herzer (2012), this paper also considered top $5 \%$.
} 
the hypothesis of cross-section independence and find that top $10 \%$ income share and Gini coefficient negatively affect crime, while opposite results are found in Neal (2015), once cross-section dependence is taken into account.

This paper draws on arguments by Nagin (1998) and Baker and Westelius (2013), and takes a further step in the literature on crime by using recently developed techniques that deal with cross-section dependence through a common factor structure. It also estimates a crime equation which embodies inequality, unemployment and deterrence measure, while previous studies such as Chintrakarn and Herzer (2012) and Neal (2015) only consider inequality. A sensitivity analysis using different measures of crime, deterrence and inequality is also carried out.

\section{Theoretical model}

Our crime model is inspired by the principles in Becker (1968) and follows the formulation in Freeman (1999), Edmark (2005), and $\mathrm{Wu}$ and $\mathrm{Wu}(2012){ }^{7}$ In this model, individuals face a choice between work and crime as sources of income. This means that work and crime are regarded as substitutes and cannot be combined. Accordingly, $W$ indicates the wage from honest work, whereas $W_{b}$ is the income from illegal activities. Like Edmark (2005), the presence of a idiosyncratic psychological cost (c) of committing a crime is also considered. This cost, that can be positive or negative, is assumed to be independent and continuously distributed over the population. The rational choice of crime satisfies the following condition:

$$
E\left(W_{b}\right)-c>E(W)
$$

According to condition (1), an individual will commit a crime if the expected return from crime, minus the psychological cost, is higher than the expected return from honest work. Formally, the expected return from crime is defined as follows:

\footnotetext{
${ }^{7}$ The model presented here is a static model as in Edmark (2005) and is sufficient to represent the argumentations of the empirical framework.
} 


$$
E\left(W_{b}\right)=(1-p) W_{b}+p\left(W_{b}-S\right)
$$

where $p$ represents the probability of being caught for an individual engaged in criminal activities and $S$ is the cost of punishment. ${ }^{8}$ The latter comprises fines, time spent in jail, low standard of living in prisons, reduction in reputation, and restrictions on future employments, among others.

The expected income from honest work is defined as follows:

$$
E(W)=(1-u) W+u A,
$$

where $u$ indicates the unemployment rate, defined as the probability of being unemployed, and $A$ is the unemployment benefit. Substituting equations (3) and (2) into condition (1), one yields the following inequality:

$$
c<\left[(1-p) W_{b}+p\left(W_{b}-S\right)\right]-[(1-u) W+u A]
$$

The above formula states that an individual chooses to commit a crime instead of working honestly if the psychological cost of committing a crime (i.e. c) is lower than the quantity on the right-hand side. Moreover, it helps elicit the effect of the parameters of the model on the supply of crime at more aggregate level (see Edmark, 2005): the higher is the right-hand side of (4), the higher is the probability for individuals to commit crimes, with an impact on the aggregate supply of crime.

The following three assumptions, taken from Freeman (1999) and Edmark (2005), are used to further specify the right-hand side of (4):

Assumption 1: Assume that $W>A$ and $u<1$ (both realistic assumptions). This implies that the right-hand side of relation (4) is increasing in $u$, because the quantity $[(1-u) W+u A]$ goes down as $u$ rises.

Assumption 2: Assume that individuals who are likely to commit crimes are low skilled workers. $W$ is likely to be far lower than the average wage of population.

\footnotetext{
${ }^{8}$ In more general terms, $S$ may also capture costs associated with the recover of stolen goods by authorities.
} 
Assumption 3: Assume that $W_{b}$ depends proportionally on the income of the higher paid $(H): W_{b}=v H$, with $v<1$, and the cost of punishment $(S)$ is proportional to the legal earnings of the criminal: $S=q W$, with $q<1$.

As a result, the right-hand side of (4) can be written as:

$$
[(1-p) v H+p(v H-q W)]-[(1-u) W+u A]
$$

Relation (5) is increasing in earning inequality, which is defined as $W_{s p}=H-W$. This implies that the greater the income inequality, the greater the incentive to commit crime. Relation (5) increases even when income of low and high paid workers rises of the same percentage.

In short, (5) is an increasing function in $u$ and $W_{s p}$, and a decreasing function in $c, p$ and $A$. The above key variables allows us to introduce the supply function of crime $\left(C^{s}\right)$ :

$$
C^{s}\left(\stackrel{+}{W}_{s p}, \bar{p}, \bar{A}, \stackrel{+}{u}, \bar{c}\right)
$$

In order to derive the effect that variables in (6) may have on crime in a general equilibrium setting, the demand function needs also to be considered, which comes from potentially black market buyers searching for illicit products (a typical example is the demand for illicit drugs). Indeed, a higher level of income is generally associated with a larger demand for crime (Edmark, 2005). This effect works in the opposite direction compared to that related to the supply function. The aggregate demand of crime $\left(C^{d}\right)$ can then be written as:

$$
C^{d}(\stackrel{+}{W})
$$

Relation (7) has implications for the effect of income on crime. For a given $H$, a rise in $W$ (and therefore a decrease in income inequality) produces a positive effect on demand, but a negative one on supply. Again, an ambiguous final effect on crime is observed through an increase in unemployment. In fact, a higher level of unemployment may negatively affect 
aggregate income, and if the impact on $W$ is higher than that of $H,{ }^{9}$ then there will be an increase in the supply and decrease in the demand of crime. Putting together relations (6) and (7), one yields the following:

$$
C^{*}\left(\stackrel{?}{W}_{s p}, \bar{p}, \bar{A}, \stackrel{?}{u}, \bar{c}\right)
$$

where $\left(C^{*}\right)$ represents the quantity of crime that equates demand and supply. The question mark above income inequality and unemployment rate indicates that it is not possible to define $a$ priori the sign of these variables. Therefore, empirically, two results are possible:

$$
\begin{gathered}
C^{*}\left(\bar{W}_{s p}, \bar{p}, \bar{A}, \bar{u}, \bar{c}\right), \\
C^{*}\left(\stackrel{+}{W}_{s p}, \bar{p}, \bar{A}, \stackrel{+}{u}, \bar{c}\right) .
\end{gathered}
$$

If (8.1) prevails, then the demand effect is stronger than the supply effect, and inequality and unemployment display a negative sign. The opposite is true when is (8.2) to prevail.

Violent crimes (aggregate violent and robbery crimes) are also considered in this work, even though our theoretical rationale is not strictly related to this kind of crimes. This is because, as argued by Grogger (2006), theoretical frameworks of property crime can be used to explain economically motivated offences that are committed through the use of violence. Further, Kelly (2000) and Edmark (2005) argue that unemployment and income inequality may affect violent crime. $^{10}$

\section{Data and econometric specification}

Our primary goal is to estimate a crime model that reflects as much as possible the theoretical framework described in section 3. More specifically, the following log-log model is estimated using annual data over the period 1978-2013 (see Becsi, 1999; Edmark, 2005;

\footnotetext{
${ }^{9}$ It is plausible to assume that an unemployment shock (for example due to a technology innovation) will have a big impact on low skilled workers (see e.g. Brynjolfsson and McAfee, 2014).

${ }^{10}$ In the strain theory of Merton (1938), it is stressed that individuals in low scale of social structure tend to feel disadvantaged and alienated. In response to this, they are more inclined to commit violent crime.
} 
Vieraitis et al., 2007; Choe, 2008; Lin, 2009): ${ }^{11}$

$$
\ln \left(\frac{O}{N}\right)_{i t}=\alpha_{i}+\beta_{1} \ln W_{s p, i t}+\beta_{2} \ln u_{i t}+\beta_{3} \ln p_{i t}+\varepsilon_{i t}
$$

where $\left(\frac{O}{N}\right)_{i t}$ is the crime rate, that is the number of crimes $(O)$ in each US state divided per 100,000 population $(N), W_{s p, i t}$ is income inequality, $u_{i t}$ is the unemployment rate, and $p_{i t}$ indicates the risk of being apprehended. ${ }^{12}$ Six categories of crimes are considered, namely property, robbery, burglary, larceny theft, auto theft, and violent. Income inequality is measured as share of personal income received by the richest $10 \%$ state population (see Frank, 2009; Chintrakarn and Herzer, 2012). The probability of being caught is not directly observable, and is usually captured by deterrence measures (see also Witt et al., 1998; Edmark, 2005; Wu and $\mathrm{Wu}, 2012)$. In this paper, prison admissions per crime (prison) and state expenditure in police defence in percentage of the total state spending (police) are used. ${ }^{13}$ In addition, equation (9) is estimated using two additional income inequality measures: top 5\% and Gini index (see also Bourguignon et al., 2003; Chintrakarn and Herzer, 2012). Finally, for a robustness check, equation (9) is also estimated with additional regressors such real per capita GDP (i.e. millions of chained 2009 US\$ per inhabitants) and population density (i.e. inhabitants per square miles). ${ }^{14}$

Our analysis uses techniques based on a common factor structure and proceeds in three steps. Notably, unit root in the variables of interest is first tested using the PANIC approach by Bai and $\mathrm{Ng}$ (2004), and then existence of cointegration is verified using the

\footnotetext{
${ }^{11}$ In the $\log -\log$ model, the estimated parameters represent the elasticity of the explanatory variables with respect to crime rate.

${ }^{12}$ The average of unemployment benefits $(A)$ and the psychological cost of crime $(c)$ are not included in specification (9) due to the lack of data (see also Edmark, 2005). In addition, we investigate the two forms of deterrence by comparing the coefficients of police and prison in different equations. For further details, see footnote 20 .

${ }^{13}$ Both measures of deterrence may suffer from simultaneity bias in crime equations. Here, this issue is addressed by using the CUP estimator that accounts for endogeneity (and serial correlation). For details, see Appendix C. In addition, prison admission may suffer from ratio bias (see Fisher and Nagin, 1978) especially when crime equations are estimated in first difference. In general, there is very little evidence of ratio bias for the US data (see Levitt, 1998).

${ }^{14}$ Data on crimes and prison admissions are taken from the Bureau of Justice Statistics, whereas data on police defense expenditures are from http://www.usgovernmentspending.com/. Data for unemployment rate are taken from US Bureau of Labour Statistics. Income inequality data are from Frank (2009) available at http://www.shsu.edu/ eco_mwf/. GDP per capita is taken from http: //www. usgovernmentspending.com/. Resident population data is from US Bureau of the Census. Total land area is from http://www.census.gov/geo/reference/state-area.html.

In Appendix A, descriptive statistics of data are reported.
} 
approach by Westerlund (2008). Lastly, the parameters in equation (9) are estimated using the CUP estimator proposed by Bai and Kao (2006).

The Bai and $\mathrm{Ng}$ (2004) approach tests for the presence of a unit root in the common factors and idiosyncratic components separately. Bai and Ng (2004) consider the following factor model:

$$
Y_{i t}=c_{i}+\lambda_{i}^{\prime} F_{t}+e_{i t}
$$

where $c_{i}$ is a polynomial trend function, $F_{t}$ is an $r \times 1$ vector of common factors, $\lambda_{i}$ is the corresponding vector of factor loadings, and $e_{i t}$ denotes the idiosyncratic error. ${ }^{15}$ Model (10) can be expressed in first difference as follows:

$$
x_{i t}=\lambda_{i}^{\prime} f_{t}+z_{i t}
$$

where $x_{i t}=\Delta X_{i t}, f_{t}=\Delta F_{t}$ and $z_{i t}=\Delta e_{i t}$. Bai and $\mathrm{Ng}$ (2004) apply the principal component analysis to $x$ to obtain $r$ estimated factors, $f_{t}$, the corresponding factor loadings, $\lambda_{i}^{\prime}$, and the estimated residuals $\hat{z}_{i t}=x_{i t}-\hat{\lambda}_{i}^{\prime} \hat{f}_{t}$. For $t=2, \ldots, T$, Bai and $\operatorname{Ng}$ (2004) define:

$$
\begin{aligned}
& \hat{e}_{i t}=\sum_{s=2}^{t} z_{i t}, i=1, \ldots, N, \\
& \hat{F}_{t}=\sum_{s=2}^{t} \hat{f}_{s}, \text { an } r \times 1 \text { factor. }
\end{aligned}
$$

The process $Y_{i t}$ in (10) may be nonstationary if one or more of the common factors are nonstationary, and/or the idiosyncratic error is nonstationary. To test for the unit root in the common factor components, Bai and Ng (2004) distinguish two different cases depending on the number of common factors selected in the data. The procedure is straightforward when one common factor is extracted from the data (the Augmented Dickey-Fuller (ADF) unit root test is applied to the estimated factor), while it is more complex when more than one factor is selected. ${ }^{16}$

\footnotetext{
${ }^{15}$ See Bai and $\mathrm{Ng}(2004)$ for the model with constant and trend.

${ }^{16}$ For details, see Bai and Ng (2004).
} 
To test the stationarity of the idiosyncratic component, Bai and Ng (2004) propose to pool the individual $A D F$ t-statistics estimated components $\hat{e}_{i t}$ :

$$
\Delta \hat{e}_{i t}=\delta_{i, 0} \hat{e}_{i, t-1}+\sum_{j=1}^{p} \delta_{i, j} \Delta \hat{e}_{i, t-j}+\mu_{i, t} .
$$

Let $A D F_{\hat{e}}^{c}(i)$ be the $A D F$ t-statistic for the $i$-th state. The asymptotic distribution of the $A D F_{\hat{e}}^{c}(i)$ coincides with the Dickey-Fuller distribution for the case of no constant. However, these individual time series tests have the same low power as those based on the initial series. Bai and Ng (2004) proposed pooled tests based on Fisher's type statistics defined as in Choi (2001) and Maddala and Wu (1999). Let $P_{\hat{e}}^{c}(i)$ be the p-value of the $A D F_{\hat{e}}^{c}(i)$, then

$$
Z_{\hat{e}}^{c}=\frac{-2 \sum_{i=1}^{N} \log P_{\hat{e}}^{c}(i)-2 N}{\sqrt{4 N}} \longrightarrow N(0,1) .
$$

After testing for unit root in the data, the analysis proceeds to check for cointegration among the variables in equation (9). To this end, the Durbin-Hausman panel cointegration test proposed by Westerlund (2008) is applied. Consider the following model

$$
\begin{aligned}
& y_{i t}=\alpha_{i}+\beta x_{i t}+z_{i t}, \\
& x_{i t}=x_{i t-1}+w_{i t} .
\end{aligned}
$$

The error term $z_{i t}$ is defined by the following equations:

$$
\begin{aligned}
& z_{i t}=\lambda_{i}^{\prime} F_{t}+e_{i t}, \\
& F_{j t}=\rho_{i} F_{j t-1}+\mu_{i t}, \\
& e_{i t}=\phi_{i} e_{i t-1}+v_{i t},
\end{aligned}
$$

where $F_{t}$ is a $k$-dimensional vector of common factors $F_{j t}$ with $j=1, \ldots, k$ and $\lambda_{i}$ is a vector of factor loadings. In equation (17), it is assumed that $\rho_{j}<1$ for all $j$, so as to ensure that $F_{t}$ is stationary. Therefore, the relationship in (14) is cointegrated if $\rho_{i}<1$ and is spurious if $\rho_{i}=1$. In order to construct the test, Westerlund (2008) uses the approach developed by 
Bai and Ng (2004). ${ }^{17}$ A test of the null hypothesis of no cointegration can be constructed as a unit root test of the recumulated sum of the defactored and first differentiated residuals. By taking firsts difference of (16), the following is obtained:

$$
\Delta z_{i t}=\lambda_{i}^{\prime} \Delta F_{t}+e_{i t}
$$

Since $\Delta z_{i t}$ is unknown, the method of the principal components is applied to its OLS estimates, which are:

$$
\Delta \hat{z}_{i t}=\Delta y_{i t}-\hat{\beta}_{i} \Delta x_{i t}
$$

where $\hat{\beta}_{i}$ is obtaining by regressing $\Delta y_{i t}$ on $\Delta x_{i t}$. Let $\lambda, \Delta F$ and $\Delta \hat{z}$ be $K \times N,(T-1) \times N$ matrices of stacked observations on $\lambda_{i}, \Delta F_{t}$ and $\Delta \hat{z}_{i t}$, respectively. The principal components estimator $\Delta \hat{F}$ of $\Delta F$ can be gained by computing $\sqrt{T-1}$ times the eigenvectors corresponding to the $K$ largest eigenvalues of the $(T-1) \times(T-1)$ matrix $\Delta \hat{z} \Delta \hat{z}^{\prime}$, and the matrix of the factor loadings is given by $\hat{\lambda}=\Delta \hat{F}^{\prime} \Delta \hat{z} / T-1$. Once $\hat{\lambda}_{i}$ and $\Delta \hat{F}_{t}$ are obtained, the defactored and first differentiated residuals are given by:

$$
\Delta \hat{e}_{i t}=\Delta \hat{z}_{i t}-\hat{\lambda}_{i}^{\prime} \Delta F_{t}
$$

that, recumulated, becomes:

$$
\hat{e}_{i t}=\sum_{j=2}^{t} \Delta e_{i j} .
$$

Westerlund (2008) shows that $\hat{e}_{i t}$ is a consistent estimates of $e_{i t}$, and this ensures that a cointegration test can be implemented using (18) with $\hat{e}_{i t}$ in place of $e_{i t}$. Therefore, the null hypothesis of no cointegration is equivalent to testing whether $\phi_{i}=1$ in the following regressions:

$$
\hat{e}_{i t}=\phi_{i} \hat{e}_{i t-1}+\text { error }
$$

Westerlund (2008) develops two panel cointegration tests that are derived by applying

\footnotetext{
${ }^{17}$ As for the assumptions in the data generating process (17)-(18), see Westerlund (2008).
} 
the Durbin-Hausman principle to (21). As for the first test, called panel test, the null and the alternative hypothesis can be formulated as $H_{0}: \phi_{i}=1$ for all $i=1, \ldots, n$ against $H_{1}^{p}: \phi_{i}=\phi_{i}$ and $\phi<1$ for all $i$, while the alternative hypothesis for the second test, named group mean test, is $H_{1}^{p}: \phi_{i}<1$ for at least some $i$. In this paper, the panel test is applied, since under the alternative hypothesis a common cointegrating relationship is shared by all the units, and the long run relationship (see equation (9)) can then be estimated. The Durbin-Hausman panel test statistics is as follows:

$$
D H_{p}=\hat{S}_{n}(\tilde{\phi}-\hat{y})^{2} \sum_{i=1}^{n} \sum_{t=2}^{T} \hat{e}_{i t-1}^{2},
$$

where $\hat{S}_{n}=\hat{\omega}_{n}^{2} /\left(\hat{\sigma}_{n}^{2}\right)^{2}$ indicates the variance ratio, with $\hat{\omega}_{i}=\frac{1}{T-1} \sum_{j=M_{i}}^{M_{i}}\left(1-\frac{j}{M_{i}+1}\right)$ $\sum_{t=j+1}^{T} \hat{v}_{i t} \hat{v}_{i t-j}$ being the consistent estimate of $\omega_{i}^{2}$, the long variance of $v_{i t}$, which are the residuals from the OLS regression in (21), and $M_{i}$ is a bandwidth parameter that determines the number of autocovariances in $v_{i t}$.

Once evidence of a cointegrating relationship is found, the parameters in equation (9) are estimated by using the CUP-FM estimator by Bai and Kao (2006):

$$
\begin{aligned}
\hat{\beta}_{C U P}= & {\left[\sum_{i=1}^{n}\left(\sum_{i=1}^{T} \hat{y}_{i, t}^{+}\left(\hat{\beta}_{C U P}\right)\left(x_{i, t}-\tilde{x}_{i}\right)^{\prime}-T\left(\hat{\lambda}_{i}^{\prime}\left(\hat{\beta}_{C U P}\right) \hat{\Delta}_{F \varepsilon i}^{+}\left(\hat{\beta}_{C U P}\right)+\hat{\Delta}_{\mu \varepsilon i}^{+}\left(\hat{\beta}_{C U P}\right)\right)\right)\right] } \\
& {\left[\sum_{i=1}^{n} \sum_{t=1}^{T}\left(x_{i, t}-\bar{x}_{i}\right)\left(x_{i, t}-\bar{x}_{i}\right)^{\prime}\right]^{-1} . }
\end{aligned}
$$

Bai and Kao (2006) proposed the CUP-FM that takes into account cross-sectional dependence and potential correlation among the error term and the explanatory variables. Bai and Kao (2006) deal with these issues by assigning a factor structure to the errors and modelling the factor process explicitly. Further, the original data for the dependent variable is transformed in order to account for the bias arising from endogeneity and serial correlation so as to re-center the limiting distribution around zero. The CUP-FM estimates the $\beta$ parameter recursively, that's the CUP-FM repeats the $\beta$ estimation using 
residuals from the FM-OLS of the previous stage until convergence. For technical details, see Appendix C.

\section{Empirical results}

In order to detect cross-correlations in the data, the pair-wise cross-state correlation coefficients of each variable along with the cross-sectional dependence (CD) test by Pesaran et al. (2008) are computed. The related results, reported in Table 1, show strong evidence of cross-correlation for all the examined variables.

Table 1: Cross-sectional dependence test results, 1978-2013.

\begin{tabular}{lcccccccc}
\hline & \multicolumn{4}{c}{ Levels } & & \multicolumn{3}{c}{ First difference } \\
\cline { 2 - 3 } \cline { 7 - 8 } Variables & $\overline{\bar{\rho}}$ & CD & $\mathrm{p}-$ value & & $\bar{\rho}$ & CD & $\mathrm{p}-$ value \\
\hline Property & 0.710 & 149.11 & 0.000 & & 0.402 & 83.25 & 0.000 \\
Robbery & 0.351 & 73.75 & 0.000 & & 0.258 & 53.48 & 0.000 \\
Burglary & 0.823 & 172.75 & 0.000 & & 0.350 & 72.57 & 0.000 \\
Auto theft & 0.517 & 108.65 & 0.000 & & 0.309 & 64.07 & 0.000 \\
Larceny theft & 0.625 & 131.17 & 0.000 & & 0.381 & 78.94 & 0.000 \\
Violent & 0.313 & 65.76 & 0.000 & & 0.283 & 58.64 & 0.000 \\
Unemployment & 0.676 & 141.89 & 0.000 & & 0.697 & 144.24 & 0.000 \\
Top 10\% & 0.871 & 182.82 & 0.000 & & 0.445 & 92.23 & 0.000 \\
Top 5\% & 0.913 & 191.81 & 0.000 & & 0.598 & 123.86 & 0.000 \\
Gini & 0.886 & 186.03 & 0.000 & & 0.553 & 114.56 & 0.000 \\
Police & 0.340 & 71.42 & 0.000 & & 0.477 & 98.74 & 0.000 \\
Prison (Property) & 0.949 & 199.37 & 0.000 & & 0.277 & 57.35 & 0.000 \\
Prison (Robbery) & 0.851 & 178.63 & 0.000 & & 0.226 & 46.78 & 0.000 \\
Prison (Burglary) & 0.957 & 200.94 & 0.000 & & 0.327 & 67.65 & 0.000 \\
Prison (Auto theft) & 0.845 & 177.42 & 0.000 & & 0.221 & 45.79 & 0.000 \\
Prison (Larceny theft) & 0.944 & 198.21 & 0.000 & & 0.244 & 50.62 & 0.000 \\
Prison (Violent) & 0.865 & 181.74 & 0.000 & & 0.226 & 46.74 & 0.000 \\
\hline \hline
\end{tabular}

Notes: Variables are expressed in log. Prison deterrence measure is expressed as inmates prison admission per crime (indicated in parenthesis). The average cross-correlation coefficient $\hat{\bar{\rho}}_{N}=(2 / N(N-$ 1)) $\sum_{i=1}^{N-1} \sum_{j=i+1}^{N} \hat{\rho}_{i j}$ is the average of the country-by-country cross-correlation coefficients $\hat{\rho}_{i j}$. CD indicates the Pesaran et al. (2008) test that is defined as $\sqrt{2 T / N(N-1)}\left(\sum_{i=1}^{N-1} \sum_{j=i+1}^{N} \hat{\rho}_{i j}\right)$.

After checking for nonstationarity of the data, cointegration among the variables in equation (9) is tested. More specifically, Table 3 reports the panel cointegration results when top $10 \%$ inequality measure is used, while Table 4 illustrates the results in case of top 5\% and Gini inequality measures. Findings in Table 3 show that our model well fits the long run relationship between the different types of crime, top $10 \%$ and deterrence 
Table 2: Panel unit root test results, 1978-2013.

\begin{tabular}{|c|c|c|}
\hline Variables & $B N_{A D F_{\hat{F}}^{c}}$ & $B N_{Z_{\hat{e}}^{c}}$ \\
\hline Property & $\begin{array}{l}1.512 \\
(1.000)\end{array}$ & $\begin{array}{c}-0.593 \\
(0.553)\end{array}$ \\
\hline Robbery & $\begin{array}{l}0.074 \\
(0.960)\end{array}$ & $\begin{array}{l}1.163 \\
(0.245)\end{array}$ \\
\hline Burglary & $\begin{array}{c}-0.340 \\
(0.907)\end{array}$ & $\begin{array}{l}0.305 \\
(0.761)\end{array}$ \\
\hline Auto theft & $\begin{array}{c}-0.021 \\
(0.950)\end{array}$ & $\begin{array}{c}-0.016 \\
(0.987)\end{array}$ \\
\hline Larceny theft & $\begin{array}{l}1.039 \\
(0.995)\end{array}$ & $\begin{array}{c}-0.593 \\
(0.553)\end{array}$ \\
\hline Violent & $\begin{array}{c}-1.345 \\
(0.597)\end{array}$ & $\begin{array}{c}-1.867 \\
(0.062)\end{array}$ \\
\hline Unemployment & $\begin{array}{c}-1.585 \\
(0.480)\end{array}$ & $\begin{array}{l}3.664 \\
(0.000)\end{array}$ \\
\hline Top $10 \%$ & $\begin{array}{c}-1.752 \\
(0.398)\end{array}$ & $\begin{array}{l}3.538 \\
(0.000)\end{array}$ \\
\hline Top $5 \%$ & $\begin{array}{c}-2.157 \\
(0.225)\end{array}$ & $\begin{array}{l}6.441 \\
(0.000)\end{array}$ \\
\hline Gini & $\begin{array}{c}-2.088 \\
(0.250)\end{array}$ & $\begin{array}{l}4.176 \\
(0.000)\end{array}$ \\
\hline Police & $\begin{array}{c}-1.846 \\
(0.353)\end{array}$ & $\begin{array}{l}1.725 \\
(0.084)\end{array}$ \\
\hline Prison (Property) & $\begin{array}{c}-1.975 \\
(0.295)\end{array}$ & $\begin{array}{l}0.187 \\
(0.852)\end{array}$ \\
\hline Prison (Robbery) & $\begin{array}{c}-1.618 \\
(0.463)\end{array}$ & $\begin{array}{l}2.022 \\
(0.043)\end{array}$ \\
\hline Prison (Burglary) & $\begin{array}{c}-1.994 \\
(0.288)\end{array}$ & $\begin{array}{l}0.340 \\
(0.955)\end{array}$ \\
\hline Prison (Auto theft) & $\begin{array}{l}0.721 \\
(0.990)\end{array}$ & $\begin{array}{l}1.331 \\
(0.183)\end{array}$ \\
\hline Prison (Larceny theft) & $\underset{(0.368)}{-1.815}$ & $\begin{array}{l}0.002 \\
(0.998)\end{array}$ \\
\hline Prison (Violent) & $\begin{array}{c}-0.847 \\
(0.792)\end{array}$ & $\begin{array}{l}2.641 \\
(0.008)\end{array}$ \\
\hline
\end{tabular}

Notes: Variables are expressed in log. Prison deterrence measure is expressed as inmates prison admission per crime (indicated in parenthesis). The number of common factors (r) selected using the BIC 3 criterion is equal to 1. The maximum number of factors is set to 4. $B N_{A D F_{\hat{F}}^{c}}$ and $B N_{Z_{\hat{e}}^{c}}$ denote the unit root tests by Bai and $\mathrm{Ng}$ (2004) on common factors and idiosyncratic components, respectively. The ADF test regression includes a constant. p-values are in parenthesis.

measures, on the grounds that strong evidence of cointegration is found. This result is also confirmed for top 5\% and Gini measures; only in one case there is no evidence of cointegration (i.e. top 5\%, unemployment and prison admissions).

In Tables 5-7, the estimation results are reported. ${ }^{18}$ They are generally in line with theoretical arguments provided in section 3 and findings in previous studies (see section 2). In particular, the supply effect of crime seems to prevail on the demand effect (see section 3), since crime elasticities with respect to inequality measures and unemployment

\footnotetext{
${ }^{18}$ Equation (9) is also estimated using standard panel one- and two-way fixed effects estimators as suggested by an anonymous referee. The results are available upon request. They contrast with the theoretical expectations, confirming previous findings in the crime literature, as shown by Neal (2015)
} 
Table 3: Panel cointegration test results, 1978-2013. Measure of inequality: Top 10\%.

\begin{tabular}{ccc}
\hline & $\begin{array}{c}\text { Equation }(9) \\
(\text { Top } 10 \%, \text { Unem., Police })\end{array}$ & $\begin{array}{c}\text { Equation }(9) \\
(\text { Top } 10 \%, \text { Unem., Prison })\end{array}$ \\
\hline Dependent variables & $\begin{array}{c}\mathrm{DH}_{\mathrm{p}} \text { test } \\
(\mathrm{p}-\text {-value })\end{array}$ & $\begin{array}{c}\mathrm{DH}_{\mathrm{p}} \text { test } \\
(\mathrm{p}-\text { value })\end{array}$ \\
\hline Property & $4.700^{* * *}$ & $6.306^{* * *}$ \\
& $(0.000)$ & $(0.000)$ \\
Robbery & $3.638^{* * *}$ & $1.502^{*}$ \\
& $(0.000)$ & $(0.067)$ \\
Burglary & $2.238^{* *}$ & $5.203^{* * *}$ \\
Auto theft & $(0.013)$ & $(0.000)$ \\
& $2.210^{* *}$ & $1.653^{* *}$ \\
Larceny theft & $(0.014)$ & $(0.049)$ \\
& $4.859^{* * *}$ & $7.506^{* * *}$ \\
Violent & $(0.000)$ & $(0.000)$ \\
& $7.055^{* * *}$ & $2.003^{* *}$ \\
& $(0.000)$ & $(0.023)$ \\
\hline
\end{tabular}

Notes: Variables are expressed in log (see equation (9)). Prison deterrence measure is expressed as inmates prison admission per crime. ${ }^{*},{ }^{* *}$, and ${ }^{* * *}$ indicate significance at $10 \%, 5 \%$, and $1 \%$ level, respectively. pvalues are reported in parenthesis.

Table 4: Panel cointegration test results, 1978-2013. Measure of inequality: Top 5\% and Gini.

\begin{tabular}{|c|c|c|c|c|}
\hline & $\begin{array}{c}\text { Equation }(9) \\
\text { (Top 5\%, Unem., Police) }\end{array}$ & $\begin{array}{c}\text { Equation (9) } \\
\text { (Top 5\%, Unem., Prison) }\end{array}$ & $\begin{array}{c}\text { Equation (9) } \\
\text { (Gini,Unem., Police) }\end{array}$ & $\begin{array}{c}\text { Equation (9) } \\
\text { (Gini,Unem., Prison) }\end{array}$ \\
\hline Dependent variables & $\begin{array}{c}\mathrm{DH}_{\mathrm{p}} \text { test } \\
(\mathrm{p}-\text { value })\end{array}$ & $\begin{array}{c}\mathrm{DH}_{\mathrm{p}} \text { test } \\
(\mathrm{p}-\text { value })\end{array}$ & $\begin{array}{c}\mathrm{DH}_{\mathrm{p}} \text { test } \\
(\mathrm{p}-\text { value })\end{array}$ & $\begin{array}{c}\mathrm{DH}_{\mathrm{p}} \text { test } \\
(\mathrm{p}-\text { value })\end{array}$ \\
\hline Property & $\begin{array}{c}3.421^{* * *} \\
(0.000)\end{array}$ & $\begin{array}{c}6.714^{* * * *} \\
(0.000)\end{array}$ & $\begin{array}{c}5.566^{* * *} \\
(0.000)\end{array}$ & $\begin{array}{c}5.473^{* * *} \\
(0.000)\end{array}$ \\
\hline Robbery & $\begin{array}{c}3.473^{* * *} \\
(0.000)\end{array}$ & $\begin{array}{l}1.472^{*} \\
(0.070)\end{array}$ & $\begin{array}{c}4.229^{* * *} \\
(0.000)\end{array}$ & $\begin{array}{l}1.709^{* *} \\
(0.044)\end{array}$ \\
\hline Burglary & $\begin{array}{c}2.612^{* * *} \\
(0.004)\end{array}$ & $\begin{array}{c}4.473^{* * *} \\
(0.000)\end{array}$ & $\begin{array}{c}6.010^{* * *} \\
(0.000)\end{array}$ & $\begin{array}{c}6.980^{* * *} \\
(0.000)\end{array}$ \\
\hline Auto theft & $\begin{array}{c}2.073^{* *} \\
(0.019)\end{array}$ & $\begin{array}{c}-0.157 \\
(0.438)\end{array}$ & $\begin{array}{c}4.017^{* * *} \\
(0.000)\end{array}$ & $\begin{array}{l}1.321^{*} \\
(0.093)\end{array}$ \\
\hline Larceny theft & $\begin{array}{l}3.442^{* * *} \\
(0.000)\end{array}$ & $\begin{array}{c}7.813^{* * *} \\
(0.000)\end{array}$ & $\begin{array}{c}5.323^{* * *} \\
(0.000)\end{array}$ & $\begin{array}{c}10.124^{* * *} \\
(0.000)\end{array}$ \\
\hline Violent & $\begin{array}{c}4.193^{* * *} \\
(0.001)\end{array}$ & $\begin{array}{c}3.012^{* * *} \\
(0.001)\end{array}$ & $\begin{array}{c}4.719^{* * *} \\
(0.000)\end{array}$ & $\begin{array}{c}3.455^{* * *} \\
(0.000)\end{array}$ \\
\hline
\end{tabular}

Notes: see Notes in Table 3.

are mostly positive. This implies that our empirical results match the conditions given in (8.2). Similar results are found by Levitt (1996), Becsi (1999), Raphael and Winter-Ebmer (2001), and Neal (2015). It should be noted that, on average, the estimated elasticities of both property and violent crime with respect to unemployment are close in magnitude to those found in Levitt (1996). The result related to prison and police show that for property crime the elasticities are on average -0.14 and -0.97 (see Tables 5-7, column 1), respectively, while the elasticities for violent crimes are -0.37 and -0.25 (see Tables 5-7, 
column 5). These findings are in line with those in Levitt (2002) and Lin (2009). ${ }^{19}$

As regards the effect of income inequality on crime, it is evident from Tables 5-7 that, on average, the elasticities of property crime with respect to all inequality measures are in line with those of violent crime. For example, a rise by $1 \%$ of top $10 \%$ generates on average an increase in property and violent crime by $3.2 \%$ and $3.3 \%$, respectively. It is also important to note that the elasticities for different type of crimes with respect to both top $10 \%$ and Gini index measures are larger than those related to top $5 \%$. In fact, for property crime, a rise by $1 \%$ in top $5 \%$ generates an increase in crime by only $2.2 \%$, a value below the effect generated by $1 \%$ increase in top $10 \%$ and Gini (i.e. $3.2 \%$ and $5.6 \%$, respectively). A similar result is observed for violent crime: here a rise by $1 \%$ in top $5 \%$ produces an increase in crime by only $2.4 \%$ compared to a rise by $3.3 \%$ and $5.2 \%$ generated by an increase of $1 \%$ in top $10 \%$ and Gini, respectively. These findings are in line with arguments developed in Allen (1996) and Demombynes and Özler (2005). In particular, they suggest that the fears of upper-income crime targets may be well founded, as Allen (1996, p.302) states that "in response to crime fears arising from inequality, upper-income crime targets have undertaken self-protective measures that may have offset criminal opportunities created by income inequality."

The findings concerning deterrence measures show that property crime is generally more sensitive to police than prison, while this difference disappears in case of violent crimes. ${ }^{20}$ This may be due to the fact that the threat of incarceration, captured by prison, is rather weak for property crimes, since in general the latter does not involve tough sanctions, while being apprehended for a violent crime is relatively more likely to lead to incarceration. This argument may also be used to explain differences among aggregate level of property crime and auto theft in terms of sensitivity to police (see columns 1 and 3 in Tables 5-7). Indeed,

\footnotetext{
${ }^{19}$ While a different model specification is proposed by Ehrlich $(1973,1975)$ that considers measures of probability of arrest, probability of conviction given arrest, and probability of incarceration given conviction separately, this paper follows Edmark (2005) and Wu and Wu (2012) and assumes that when a criminal is caught is incarcerated. The reason for this is that there is no available data for the three measures used by Ehrlich $(1973,1975)$ over a long time span for all the US states.

${ }^{20}$ In order to test for the equality of the estimated coefficients for deterrence measures across different specifications, we run the Z-test suggested by Paternoster et al. (1998). In particular, we find that the coefficients of prison and police are statistically different for property crime, whereas for violent crime those are statistically different only when the Gini inequality measure is considered. The results are available upon request.
} 
Table 5: Estimation results of equation (9), 1978-2013. Measure of inequality: Top 10\%.

\begin{tabular}{ccccccc}
\hline Variables & Property & Burglary & Auto theft & Larceny theft & Violent & Robbery \\
\hline Top 10\% & $2.985^{* * *}$ & $1.428^{* * *}$ & $1.711^{* * *}$ & $3.032^{* * *}$ & $2.655^{* * *}$ & $1.269^{* * *}$ \\
& $(0.244)$ & $(0.210)$ & $(0.213)$ & $(0.232)$ & $(0.194)$ & $(0.160)$ \\
Unemployment & $0.618^{* * *}$ & $0.721^{* * *}$ & -0.038 & $0.550^{* * *}$ & $0.271^{* * *}$ & $0.217^{* * *}$ \\
& $(0.048)$ & $(0.041)$ & $(0.042)$ & $(0.046)$ & $(0.038)$ & $(0.032)$ \\
& $-1.039^{* * *}$ & $-0.864^{* * *}$ & $-0.621^{* * *}$ & $-1.030^{* * *}$ & $-0.324^{* * *}$ & $-0.680^{* * *}$ \\
& $(0.136)$ & $(0.117)$ & $(0.116)$ & $(0.129)$ & $(0.109)$ & $(0.092)$ \\
\hline Volice & Property & Burglary & Auto theft & Larceny theft & Violent & Robbery \\
\hline Top 10\% & $3.547^{* * *}$ & $1.711^{* * *}$ & $4.375^{* * *}$ & $3.919^{* * *}$ & $3.977^{* * *}$ & $2.943^{* * *}$ \\
& $(0.261)$ & $(0.225)$ & $(0.211)$ & $(0.246)$ & $(0.195)$ & $(0.162)$ \\
Unemployment & $0.697^{* * *}$ & $0.797^{* * *}$ & $0.114^{* * *}$ & $0.626^{* * *}$ & $0.281^{* * *}$ & $0.201^{* * *}$ \\
& $(0.048)$ & $(0.042)$ & $(0.040)$ & $(0.045)$ & $(0.037)$ & $(0.031)$ \\
Prison & $-0.104^{*}$ & -0.031 & $-0.545^{* * *}$ & $-0.181^{* * *}$ & $-0.335^{* * *}$ & $-0.361^{* * *}$ \\
& $(0.064)$ & $(0.049)$ & $(0.041)$ & $(0.062)$ & $(0.047)$ & $(0.033)$ \\
\hline
\end{tabular}

Notes: Variables are expressed in log (see equation (9)). Prison deterrence measure is expressed as inmates prison admission per crime. Standard errors are in parenthesis. ${ }^{*},{ }^{* *},{ }^{* * *}$ indicate significance at $10 \%, 5 \%$ and $1 \%$ level, respectively.

Table 6: Estimation results of equation (9), 1978-2013. Measure of inequality: Top 5\%.

\begin{tabular}{ccccccc}
\hline Variables & Property & Burglary & Auto theft & Larceny theft & Violent & Robbery \\
\hline Top 5\% & $2.132^{* * *}$ & $0.974^{* * *}$ & $1.203^{* * *}$ & $2.183^{* * *}$ & $1.918^{* * *}$ & $0.912^{* * *}$ \\
& $(0.183)$ & $(0.156)$ & $(0.158)$ & $(0.174)$ & $(0.145)$ & $(0.121)$ \\
Unemployment & $0.753^{* * *}$ & $0.778^{* * *}$ & 0.040 & $0.692^{* * *}$ & $0.395^{* * *}$ & $0.282^{* * *}$ \\
& $(0.050)$ & $(0.043)$ & $(0.044)$ & $(0.048)$ & $(0.040)$ & $(0.034)$ \\
Police & $-1.111^{* * *}$ & $-0.904^{* * *}$ & $-0.649^{* * *}$ & $-1.098^{* * *}$ & $-0.381^{* * *}$ & $-0.702^{* * *}$ \\
& $(0.134)$ & $(0.115)$ & $(0.115)$ & $(0.128)$ & $(0.108)$ & $(0.091)$ \\
\hline Variables & Property & Burglary & Auto theft & Larceny theft & Violent & Robbery \\
\hline Top 5\% & $2.258^{* * *}$ & $0.819^{* * *}$ & - & $2.613^{* * *}$ & $2.856^{* * *}$ & $2.113^{* * *}$ \\
& $(0.196)$ & $(0.171)$ & & $(0.185)$ & $(0.146)$ & $(0.123)$ \\
Unemployment & $0.849^{* * *}$ & $0.874^{* * *}$ & - & $0.798^{* * *}$ & $0.446^{* * *}$ & $0.342^{* * *}$ \\
& $(0.051)$ & $(0.045)$ & & $(0.048)$ & $(0.039)$ & $(0.033)$ \\
Prison & -0.030 & 0.050 & - & $-0.122^{* * *}$ & $-0.321^{* * *}$ & $-0.352^{* * *}$ \\
& $(0.064)$ & $(0.050)$ & & $(0.063)$ & $(0.047)$ & $(0.033)$ \\
\hline
\end{tabular}

Notes: The auto theft crime regression is not estimated when Prison is considered, since cointegration test results are not statically significant (see Table 4). For further details, see Notes in Table 5.

Table 7: Estimation results of equation (9), 1978-2013. Measure of inequality: Gini.

\begin{tabular}{ccccccc}
\hline Variables & Property & Burglary & Auto theft & Larceny theft & Violent & Robbery \\
\hline Gini & $4.726^{* * *}$ & $2.611^{* * *}$ & $2.777^{* * *}$ & $4.788^{* * *}$ & $4.003^{* * *}$ & $2.115^{* * *}$ \\
& $(0.324)$ & $(0.288)$ & $(0.280)$ & $(0.306)$ & $(0.249)$ & $(0.215)$ \\
Unemployment & $0.646^{* * *}$ & $0.760^{* * *}$ & -0.013 & $0.572^{* * *}$ & $0.302^{* * *}$ & $0.230^{* * *}$ \\
& $(0.049)$ & $(0.043)$ & $(0.041)$ & $(0.048)$ & $(0.037)$ & $(0.032)$ \\
Police & $-0.765^{* * *}$ & $-0.681^{* * *}$ & $-0.430^{* * *}$ & $-0.777^{* * *}$ & -0.050 & $-0.506^{* * *}$ \\
& $(0.144)$ & $(0.129)$ & $(0.122)$ & $(0.136)$ & $(0.112)$ & $(0.096)$ \\
\hline Variables & Property & Burglary & Auto theft & Larceny theft & Violent & Robbery \\
\hline Gini & $6.571^{* * *}$ & $4.586^{* * *}$ & $6.694^{* * *}$ & $6.730^{* * *}$ & $6.467^{* * *}$ & $5.003^{* * *}$ \\
& $(0.340)$ & $(0.291)$ & $(0.266)$ & $(0.323)$ & $(0.259)$ & $(0.211)$ \\
Unemployment & $0.639^{* * *}$ & $0.699^{* * *}$ & $0.108^{* * *}$ & $0.571^{* * *}$ & $0.256^{* * *}$ & $0.157^{* * *}$ \\
& $(0.048)$ & $(0.043)$ & $(0.038)$ & $(0.045)$ & $(0.036)$ & $(0.029)$ \\
Prison & $-0.281^{* * *}$ & $-0.247^{* * *}$ & $-0.607^{* * *}$ & $-0.321^{* * *}$ & $-0.467^{* * *}$ & $-0.468^{* * *}$ \\
& $(0.063)$ & $(0.049)$ & $(0.040)$ & $(0.065)$ & $(0.049)$ & $(0.033)$ \\
\hline
\end{tabular}

Notes: See Notes in Table 5. 
auto theft involves both criminal and illegal activities of stealing and selling cars, which are generally sanctioned as violent crimes (see Longman, 2006; Rosenmerkel et al., 2009).

With regard to the impact that labour market conditions may have on the two main forms of crimes, the results show that property crimes are on average more sensitive to unemployment than violent crimes (see also Levitt, 1996; Donohue and Levitt, 2001; Raphael and Winter-Ebmer, 2001), ${ }^{21}$ and a rise by $1 \%$ in unemployment rate generates on average an increase by $0.7 \%$ and $0.3 \%$ in property and violent crime, respectively.

Our analysis highlights that income inequality plays a crucial role in affecting all types of crimes. Therefore, reducing inequality should then be a target in order to combat crime. Inequality not only poses moral questions, but also impacts on the economic growth trough an increase in crime. In fact, higher crime rates are likely to reduce the return to legal activities, and may provide further incentives for individuals to seek illegal income, with an adverse effect on investments and human capital accumulation (see Josten, 2003). Therefore, redistributive policies that tend to sustain personal income of more disadvantaged individuals may be recommend to this end, especially when unemployment is high, with a particular beneficial impact on property crime.

Turning to the role of deterrence on crime, police enforcement activities seem to exert a different effect on the two main types of crimes: a rise by $1 \%$ of police causes on average a reduction in property and violent crime by $0.98 \%$ and $0.25 \%$, respectively. This implies that, in those states where violent crimes are significantly high, a rise in police forces may not produce the expected result in terms of offenses reduction. In addition, any reinforcement of imprisonment policy may be not particularly convenient for a state government. This is because the effect of prison on property crime is much weaker than that of police (the average estimated elasticity of property crime with respect to prison is rather small and equal to $0.14 \%$ ) and the effect on violent crime is only slightly larger than that of police (the average estimated elasticity of violent crime with respect to prison is $0.37 \%$ ). As a result, pursuing tough imprisonment policies may not lead to significant

\footnotetext{
${ }^{21}$ It should be noted that auto theft crime regression shows no cointegration for top $5 \%$, unemployment and prison, while it is instead statistically significant with top $10 \%$, unemployment and Gini measures (see Table 4).
} 
gains in terms of a reduction in crime, and states may face unsustainable costs, ${ }^{22}$ with no benefit for the society (see Henrichson and Delaney, 2012; Kearney et al., 2014). ${ }^{23}$

As a final step, robustness checks are carried out to investigate the sensitivity of the results when additional regressors are included in equation (9). In particular, two additional variables are added to the baseline equation: the population density and GDP per capita (see equation (23) in Appendix B). ${ }^{24}$ The population density is an important demographic factor that may affect crime. In general, there are studies (see e.g. Christens and Speer, 2005; Browning et al., 2010) suggesting that higher density implies a significant surveillance effect inhibiting crime (i.e. the so-called "eyes on the street" effect discussed in Jacobs (2010)). ${ }^{25}$ GDP per capita, as an indicator of personal wealth and economic conditions, will probably negatively affect crime rates (see e.g. Arvanites and Defina, 2006). The results in Table B1 (see Appendix B) show that cointegration exists in case of the extended model for violent and property crime in both the formulations with top $10 \%$ and top $5 \%$ inequality measures. ${ }^{26}$ The estimation results show that the variables have the expected signs and population density is always statistically significant in all the formulations, whereas GDP per capita is only statistically significant for property crime (see Tables B2 and B3 in Appendix B). But, most importantly, it emerges that the addition of control variables to the original model formulation does not alter the general results.

\footnotetext{
${ }^{22}$ Using the life satisfaction approach to non-market valuation Manning et al. (2016) reveal that the intangible costs of crime can be significant when considered alongside what a state may spend on policing to achieve a reduction in crime.

${ }^{23} \mathrm{~A}$ reinforcement of imprisonment policies may also produce a rise in wage inequality with an increasing impact on crime (Western et al., 2001; Western and Pettit, 2002). Individuals that are released from prison may suffer from low earnings and irregular employment. This may cause deterioration in job skills, and undermine potential connection with job opportunities. All this may produce an increase in crime (see Hagan, 1993).

${ }^{24}$ The choice of these two variables is dictated by the availability of data.

${ }^{25}$ Levine et al. (2012) also suggests that large urban density increases job opportunities and facilitate education access with an impact on crime.

${ }^{26}$ Similar results are valid for different formulations of crime (i.e. robbery, burglary, auto theft, larceny theft) and Gini index, but are not reported here for space concerns. These results are available from authors by request.
} 


\section{Conclusions}

This paper aims to estimate the long run relationship between crime, unemployment, inequality and deterrence in the US at state level over the period 1978-2013 using nonstationary panels based on a common factor structure. Several measures of crime, inequality and deterrence are considered.

The paper makes some contributions to the empirical literature on crime in the US. To the best of our knowledge, this is the first paper to estimate the long run relationship between crime, unemployment, inequality, and deterrence in the US using nonstationary panels. Further, this paper uses factor models to deal with cross-section dependence, which widely features crime data, and applies the CUP-FM estimator developed by Bai and Kao (2006) that controls for endogeneity and serial correlation. Moreover, a sensitivity analysis for crime using different measures of crime, deterrence and inequality is carried out.

Our empirical analysis offers four main results. First, our crime model well fits the long run relationship between different type of crimes, inequality, unemployment and deterrence measures. Second, the impact of inequality and unemployment on crime is positive, whereas that of deterrence is negative. Third, crimes appear to be more sensitive to share of total income within a larger population. Fourth, the two measures of deterrence exert a similar effect on violent crimes, while police activities are more effective to combat property crimes.

Our results may be relevant not only because of their implications for panel studies on crime, but also from a policy view: $i$ ) if inequality plays a role in determining crime, then policies aiming to sustain personal income of more disadvantaged people may help to weaken crime; $i i)$ police enforcement activities may not produce a relevant reduction in violent crimes, while the opposite is true for property crimes; and iii) a reinforcement of imprisonment policy may result in unsustainable social costs.

This paper may have some limitations. While the use of data at state level allows us to overcome the aggregation-bias (Chiricos, 1987), further disaggregation might help identify socio-cultural and ethnic backgrounds factors. These factors can be captured at individual 
level, but with the caveat that only short run effects can be estimated.

Future research in long panels setting may consider interactive fixed effects representing unobservable factors related to psychological cost of committing a crime. Further, potential changes in legislation that can affect crime may be also taken into account using macro panels which consider breaks in the data. 


\section{References}

Allen, R. (1996). Socioeconomic conditions and property crime. American Journal of Economics and Sociology, 55(3):293-308.

Arvanites, T. and Defina, R. (2006). Business cycles and street crime. Criminlogy, 44(1):139-164.

Bai, J. and Kao, C. (2006). On the estimation and inference of a panel cointegration model with cross sectional dependence. In Baltagi, B., editor, Panel Data Econometrics: Theoretical Contributions and Empirical Applications, pages 3-30. Emerald Group Publishing Limited, Bingley, UK.

Bai, J. and Ng, S. (2004). A PANIC attack on unit roots and cointegration. Econometrica, 72(4):1127-1177.

Baker, M. and Westelius, N. (2013). Crime, expectations, and the deterrence hypothesis. In Miceli, T. J. and Baker, M. J., editors, Research Handbook on Economic Models of Law, pages 235-280. Edward Elgar Publishing, Northampton, US.

Becker, G. (1968). Crime and punishment: An economic approach. Journal of Political Economy, 76(2):169-217.

Becsi, Z. (1999). Economics and crime in the states. Economic Review-Federal Reserve Bank of Atlanta, 84(1):38-56.

Birkel, C. (2014). The analysis of non-stationary pooled time series cross-section data. International Journal of Conflict and Violence, 8(2):222-242.

Blomquist, J. and Westerlund, J. (2014). A non-stationary panel data investigation of the unemployment-crime relationship. Social Science Research, 44:114-125.

Bourguignon, F., Nuñez, J., and Sanchez, F. (2003). A structural model of crime and inequality in colombia. Journal of the European Economic Association, 1(2-3):440-449. 
Browning, C., Byron, R., Calder, C., Krivo, L., Kwan, M.-P., Lee, J.-Y., and Peterson, R. (2010). Commercial density, residential concentration, and crime: Land use patterns and violence in neighborhood context. Journal of Research in Crime and Delinquency, 47(3):329-357.

Brynjolfsson, E. and McAfee, A. (2014). The second machine age: Work, progress, and prosperity in a time of brilliant technologies. WW Norton \& Company, New York, US.

Chintrakarn, P. and Herzer, D. (2012). More inequality, more crime? A panel cointegration analysis for the united states. Economics Letters, 116(3):389-391.

Chiricos, T. (1987). Rates of crime and unemployment: An analysis of aggregate research evidence. Social Problems, 34(2):187-212.

Choe, J. (2008). Income inequality and crime in the United States. Economics Letters, 101(1):31-33.

Choi, I. (2001). Unit root tests for panel data. Journal of International Money and Finance, 20(2):249-272.

Christens, B. and Speer, P. (2005). Predicting violent crime using urban and suburban densities. Behavior and Social Issues, 14(2):113-127.

Demombynes, G. and Özler, B. (2005). Crime and local inequality in South Africa. Journal of Development Economics, 76(2):265-292.

Donohue, J. and Levitt, S. (2001). The impact of legalized abortion on crime. Quarterly Journal of Economics, 116(2):379-420.

Doyle, J., Ahmed, E., and Horn, R. (1999). The effects of labor markets and income inequality on crime: Evidence from panel data. Southern Economic Journal, 65(4):717738.

Edmark, K. (2005). Unemployment and crime: Is there a connection? The Scandinavian Journal of Economics, 107(2):353-373. 
Ehrlich, I. (1973). Participation in illegitimate activities: A theoretical and empirical investigation. The Journal of Political Economy, 81(3):521-565.

Ehrlich, I. (1975). The deterrent effect of capital punishment: A question of life and death. The American Economic Review, 65(3):397-417.

Fisher, F. and Nagin, D. (1978). On the feasibility of identifying the crime function in a simultaneous model of crime rates and sanction levels. In Blumstein, A., Cohen, J., and Nagin, D., editors, Deterrence and Incapacitation: Estimating the Effects of Criminal Sanctions on Crime Rates, pages 361-399. National Academies Press, Washington DC, US.

Frank, M. (2009). Inequality and growth in the United States: Evidence from a new state-level panel of income inequality measures. Economic Inquiry, 47(1):55-68.

Freeman, R. (1999). The economics of crime. Handbook of Labor Economics, 3:3529-3571.

Gould, E., Weinberg, B., and Mustard, D. (2002). Crime rates and local labor market opportunities in the United States: 1979-1997. Review of Economics and Statistics, 84(1):45-61.

Grogger, J. (2006). An economic model of recent trends in violence. In Blumstein, A. and Wallman, J., editors, The Crime Drop in America, pages 266-287. Cambridge Univ. Press, Cambridge, UK, 2nd edition.

Hagan, J. (1993). The social embeddedness of crime and unemployment. Criminology, $31(4): 465-491$.

Henrichson, C. and Delaney, R. (2012). The price of prisons: What incarceration costs taxpayers. Federal Sentencing Reporter, 25(1):68-80.

Jacobs, J. (2010). The death and life of great American cities. In Bridge, G. and Watson, S., editors, The Blackwell City Reader, chapter 29, pages 273-277. John Wiley \& Sons, Chichester, West Sussex, UK. 
Johnson, R. and Raphael, S. (2012). How much crime reduction does the marginal prisoner buy? Journal of Law and Economics, 55(2):275-310.

Joliffe, I. (2002). Principal Component Analysis. Springer, New York, US, 2nd edition.

Josten, S. (2003). Inequality, crime and economic growth. A classical argument for distributional equality. International Tax and Public Finance, 10(4):435-452.

Kearney, M., Harris, B., Jácome, E., and Parker, L. (2014). Ten economic facts about crime and incarceration in the United States. Policy memo, Brookings Institution technical report.

Kelly, M. (2000). Inequality and crime. Review of Economics and Statistics, 82(4):530-539.

Levine, J., Grengs, J., Shen, Q., and Shen, Q. (2012). Does accessibility require density or speed? a comparison of fast versus close in getting where you want to go in us metropolitan regions. Journal of the American Planning Association, 78(2):157-172.

Levitt, S. (1996). The effect of prison population size on crime rates: Evidence from prison overcrowding legislation. Quarterly Journal of Economics, 111(2):319-351.

Levitt, S. (1998). Why do increased arrest rates appear to reduce crime: Deterrence, incapacitation, or measurement error? Economic Inquiry, 36(3):353-372.

Levitt, S. (2002). Using electoral cycles in police hiring to estimate the effects of police on crime: Reply. The American Economic Review, 92(4):1244-1250.

Levitt, S. (2004). Understanding why crime fell in the 1990s: Four factors that explain the decline and six that do not. The Journal of Economic Perspectives, 18(1):163-190.

Lin, M.-J. (2009). More police, less crime: Evidence from us state data. International Review of Law and Economics, 29(2):73-80.

Longman, M. (2006). The problem of auto theft. In Stauffer, E. and Bonfanti, M., editors, Forensic Investigation of Stolen-Recovered and Other Crime-Related Vehicles, pages 121. Academic Press, Elsevier, Burlington, US. 
Maddala, G. and Wu, S. (1999). A comparative study of unit root tests with panel data and a new simple test. Oxford Bulletin of Economics and Statistics, 61(S1):631-652.

Malby, S. and Davis, P. (2012). Monitoring the impact of economic crisis on crime. Technical report, United Nations (Office on Drugs and Crime) Report.

Manning, M., Fleming, C., and Ambrey, C. (2016). Life satisfaction and individual willingness to pay for crime reduction. Regional Studies, forthcoming:1-16.

Marvell, T. and Moody, C. (1994). Prison population growth and crime reduction. Journal of Quantitative Criminology, 10(2):109-140.

McDowall, D. and Loftin, C. (2009). Do US city crime rates follow a national trend? The influence of nationwide conditions on local crime patterns. Journal of Quantitative Criminology, 25(3):307-324.

Merton, R. (1938). Social structure and anomie. American Sociological Review, 3(5):672682.

Nagin, D. (1998). Criminal deterrence research at the outset of the twenty-first century. Crime and Justice, 23:1-42.

Nagin, D. (2013). Deterrence: A review of the evidence by a criminologist for economists. Annual Review of Economics, 5(1):83-105.

Narayan, P., Nielsen, I., and Smyth, R. (2010). Is there a natural rate of crime? American Journal of Economics and Sociology, 69(2):759-782.

Neal, T. (2015). The unbiased estimation of heterogeneous coefficients in panel data models with common factors and feedback effects. Mimeo, University of New South Wales.

Paternoster, R., Brame, R., Mazerolle, P., and Piquero, A. (1998). Using the correct statistical test for the equality of regression coefficients. Criminology, 36(4):859-866.

Pesaran, M. H., Ullah, A., and Yamagata, Y. (2008). A bias-adjusted LM test of error cross section independence. Econometrics Journal, 11(1):105-127. 
Raphael, S. and Winter-Ebmer, R. (2001). Identifying the effect of unemployment on crime. Journal of Law and Economics, 44(1):259-283.

Rosenmerkel, S., Durose, M., and Farole Jr, D. (2009). Felony sentences in state courts, 2006: Statistical tables. Statistical report (NCJ 226846), Bureau of Justice Statistics, U.S. Department of Justice.

Spelman, W. (2006). The limited importance of prison expansion. In Blumstein, A. and Walman, J., editors, The Crime Drop in America, pages 97-129. Cambridge University Press, New York, US, 2nd edition.

Vieraitis, L., Kovandzic, T., and Marvell, T. (2007). The criminogenic effects of imprisonment: Evidence from state panel data, 1974-2002. Criminology \&6 Public Policy, 6(3):589-622.

Westerlund, J. (2008). Panel cointegration tests of the Fisher effect. Journal of Applied Econometrics, 23(2):193-233.

Western, B., Kling, J., and Weiman, D. (2001). The labor market consequences of incarceration. Crime \& Delinquency, 47(3):410-427.

Western, B. and Pettit, B. (2002). Beyond crime and punishment: Prisons and inequality. Contexts, 1(3):37-43.

Witt, R., Clarke, A., and Fielding, N. (1998). Crime, earnings inequality and unemployment in England and Wales. Applied Economics Letters, 5(4):265-267.

Wu, D. and Wu, Z. (2012). Crime, inequality and unemployment in England and Wales. Applied Economics, 44(29):3765-3775. 
Appendix A: Descriptive statistics 
Table A1: Descriptive statistics. Crime data

\begin{tabular}{|c|c|c|c|c|c|c|c|c|c|c|c|c|}
\hline & \multicolumn{2}{|c|}{ Property } & \multicolumn{2}{|c|}{ Burglary } & \multicolumn{2}{|c|}{ Auto theft } & \multicolumn{2}{|c|}{ Larceny theft } & \multicolumn{2}{|c|}{ Violent } & \multicolumn{2}{|c|}{ Robbery } \\
\hline & Mean & Std dev & Mean & Std dev & Mean & Std dev & Mean & Std dev & Mean & Std dev & Mean & Std dev \\
\hline Alabama & 3963.24 & 302.32 & 1075.74 & 151.70 & 294.51 & 45.09 & 2593.04 & 238.35 & 514.65 & 123.36 & 130.96 & 24.15 \\
\hline Alaska & 4329.45 & 984.14 & 815.53 & 297.18 & 451.86 & 137.34 & 3055.47 & 583.97 & 609.79 & 82.33 & 94.62 & 21.03 \\
\hline Arizona & 5840.18 & 1280.01 & 1359.33 & 426.13 & 671.03 & 273.01 & 3817.60 & 851.56 & 561.17 & 87.04 & 149.32 & 20.80 \\
\hline Arkansas & 3777.99 & 356.89 & 1042.44 & 113.62 & 240.96 & 51.82 & 2494.60 & 270.59 & 460.32 & 85.92 & 92.28 & 18.94 \\
\hline California & 4537.23 & 1425.02 & 1184.33 & 557.44 & 703.75 & 187.77 & 2649.14 & 769.00 & 740.19 & 213.45 & 270.14 & 91.28 \\
\hline Colorado & 4711.09 & 1372.89 & 1063.44 & 493.17 & 405.10 & 88.20 & 3238.17 & 859.81 & 428.81 & 84.55 & 99.94 & 30.68 \\
\hline Connecticut & 3677.19 & 1089 & 873.28 & 413.69 & 451.93 & 179.18 & 2351.98 & 525.03 & 374.54 & 81.20 & 159.27 & 45.12 \\
\hline Delaware & 4265.38 & 899.97 & 954.56 & 286.80 & 342.29 & 94.66 & 2971.28 & 573.07 & 593.31 & 101.34 & 161.02 & 30.22 \\
\hline Florida & 5731. & 1483.76 & 1548.16 & 549.50 & 539.23 & 205.15 & 3644.51 & 811.39 & 876.78 & 213.37 & 261.90 & 88.79 \\
\hline Georgia & 4648.04 & 777.38 & 1200.05 & 293.23 & 457.03 & 117.87 & 2990.94 & 503.01 & 540.78 & 110.50 & 185.69 & 41.64 \\
\hline Hawaii & 5256.91 & 1128.23 & 1089.05 & 366.29 & 478.35 & 146.01 & 3703.47 & 761.57 & 260.78 & 17.63 & 105.87 & 30.71 \\
\hline Idaho & 3244.80 & 742.90 & 728.98 & 228.52 & 171.52 & 44.45 & 2344.32 & 511.85 & 253.19 & 28.25 & 21.75 & 8.24 \\
\hline Illino & 4086.64 & 927.41 & 931.44 & 306.94 & 467.74 & 157.30 & 2691.36 & 491.44 & 719.95 & 181.99 & 273.34 & 85.49 \\
\hline Indiana & 3699.89 & 414.98 & 859.44 & 161.41 & 351.63 & 72.77 & 2488. & 233.66 & 378.76 & 75.99 & 111.85 & 13.53 \\
\hline Iowa & 3321.56 & 636.16 & 735.18 & 161.80 & 178.46 & 34.24 & 2408.24 & 466.90 & 261.99 & 45.88 & 41.91 & 6.96 \\
\hline Kansas & 4123.51 & 559.18 & 991.58 & 265.16 & 267.61 & 43.01 & 2863.83 & 325.05 & 392.88 & 46.86 & 86.11 & 22.67 \\
\hline & 2763.83 & 214.73 & 755.12 & 123.77 & 208.83 & 32.90 & 1800.05 & & 307.66 & 71.93 & 84.98 & 8.52 \\
\hline Lou & 4713.92 & 709.95 & 1209.35 & 193.99 & 423.43 & 131.65 & 3081 & 464.48 & 726.88 & 142.27 & 191.57 & 52.57 \\
\hline $\mathrm{Ma}$ & 3064.94 & 559.01 & 737.26 & 226 & 140.60 & 46.96 & 2187 & .07 & 137.06 & 27.76 & 25.62 & 3.92 \\
\hline Mar & 4372.58 & 864.48 & 989.99 & 314.41 & 531.69 & 146.71 & 2850 & 512.08 & 775.18 & 141.04 & 302.15 & 77.35 \\
\hline Massachusetts & 3495.56 & 1065.97 & 878.75 & 377.50 & 607.15 & 319.49 & 2009.65 & 392.72 & 558.22 & 109.49 & 151.80 & 47.73 \\
\hline Michigan & 4333.02 & 1203.63 & 1059.57 & 391.60 & 573.94 & 165.18 & 2699.50 & 705.81 & 626.24 & 113.65 & 189.41 & 65.64 \\
\hline Minnesota & 3615.89 & 628.01 & 777.33 & 251.31 & 278.25 & 68.95 & 2559.96 & 365.79 & 272.98 & 45.19 & 90.42 & 16.35 \\
\hline & 3364.81 & & 1069.37 & 138.60 & 237.86 & 80.78 & 2069 & 379.37 & 335.79 & 69.10 & 97.08 & 26.56 \\
\hline & 4088.31 & 424 & 986.13 & 267 & 418.76 & 84.75 & 2683 & 233.81 & 551.04 & 91.13 & 161.28 & 44.61 \\
\hline & 3722.57 & & 588.01 & 204 & 226.63 & 44.37 & 2895 & 6.06 & 225.49 & 66.40 & 25.11 & 6.12 \\
\hline Nebraska & 3586.97 & 450.47 & 649.35 & 126.27 & 255.93 & 73.31 & 2681.70 & 348.08 & 299.42 & 69.53 & 62.36 & 9.57 \\
\hline Nevada & 5013.29 & 1471.47 & 1406.65 & 617.82 & 657.37 & 185.96 & 2949.46 & 902.28 & 709.94 & 115.84 & 281.86 & 73.49 \\
\hline New Hampshire & 2788.86 & 730.05 & 591.63 & 279.24 & 172.92 & 67.23 & 2024.31 & 406.91 & 145.96 & 28.24 & 30.58 & 6.31 \\
\hline & 3647.47 & 1188.60 & 850.71 & 397.99 & 533.93 & 237.63 & 2263.11 & 604.62 & 473.84 & 122.59 & 219.80 & 65.93 \\
\hline & 4971.48 & & 1361.97 & & 1.17 & 98.76 & & & 716.66 & & 121.93 & 23.08 \\
\hline $\mathrm{Ner}$ & 3632. & & 872.86 & 524 & 496.76 & 304.12 & 2263 & & 748.68 & 281.04 & 373.11 & 188.28 \\
\hline North Carolina & 4230.13 & 547.07 & 1283.32 & 165.60 & 259.17 & 60.59 & 2687.64 & 362.30 & 492.89 & 95.97 & 128.90 & 38.49 \\
\hline North Dakota & 2420.59 & 331.90 & 380.31 & 51.94 & 150.47 & 22.32 & 1889.77 & 304.81 & 103.36 & 64.63 & 10.28 & 3.46 \\
\hline Ohio & 3917.11 & 459.27 & 975.17 & 179.66 & 359.63 & 87.14 & 2581.80 & 262.86 & 401.97 & 73.64 & 164.50 & 26.83 \\
\hline Oklahoma & 4389.34 & 639.76 & 1258.17 & 280.25 & 430.60 & 100.48 & 2700.57 & 371.17 & 496.90 & 73.97 & 102.75 & 16.99 \\
\hline & 5021.04 & 110 & 1112 & 489 & 429.62 & 124.64 & 3462.20 & 63 & 413.04 & 113.25 & 119.73 & 45.63 \\
\hline & 2713. & & & & 319 & & & & 39 & 41 & 156.66 & 20 \\
\hline & 3807.23 & 970.33 & 934.66 & 381.29 & 547.91 & 224.24 & 2324.64 & 389.64 & 328.75 & 65.50 & 93.06 & 20.03 \\
\hline Carolina & 4507.86 & 408.81 & 1218.06 & 206.97 & 337.27 & 56.99 & 2952.53 & 294.39 & 771.87 & 144.87 & 133.31 & 28.40 \\
\hline South Dakota & 2382.22 & 430.81 & 478.46 & 102.16 & 114.40 & 18.98 & 1789.58 & 329.78 & 178.76 & 52.98 & 16.83 & 3.11 \\
\hline Tennessee & 4053.51 & 396.88 & 1138.66 & 152.03 & 437.07 & 132.99 & 2477.78 & 318.03 & 628.28 & 129.34 & 175.60 & 27.76 \\
\hline Texas & 5139.02 & 1126.83 & 31333.88 & 453.05 & 533.26 & 182.69 & 3271.90 & 561.58 & 574.83 & 106.67 & 182.40 & 41.41 \\
\hline Uta & 4586.88 & 877.45 & 799.72 & 226.10 & 286.96 & 61.77 & 3500.18 & & 262.29 & 37.92 & 57.75 & 11.57 \\
\hline & 3265.02 & 859.08 & 831.43 & & 152.00 & 65.83 & 2281.59 & 504.60 & 129.53 & 19.46 & 16.56 & 6.47 \\
\hline & 3284.70 & 673.03 & 640.22 & 246.02 & 229.79 & 60.89 & 2414.40 & 423.46 & 296.40 & 48.02 & 104.90 & 21.40 \\
\hline Washingto & 5230.76 & 915.46 & 1238.54 & 399.27 & 474.25 & 137.46 & 3517.96 & 624.77 & 404.44 & 69.87 & 114.78 & 20.10 \\
\hline West Virginia & 2310.07 & 155.73 & 614.97 & 55.45 & 174.01 & 26.52 & 1521.11 & 143.88 & 226.83 & 59.25 & 42.23 & 4.64 \\
\hline Wisconsin & 3428.13 & 659.91 & 652.81 & 188.69 & 259.13 & 78.68 & 2516.19 & 444.91 & 238.29 & 37.53 & 84.83 & 16.93 \\
\hline Wyoming & 3535.90 & 671.53 & 600.69 & 166.33 & 166.42 & 65.85 & 2768.78 & 476.32 & 268.12 & 49.27 & 20.45 & 9.50 \\
\hline
\end{tabular}


Table A2: Descriptive statistics. Socioeconomic data

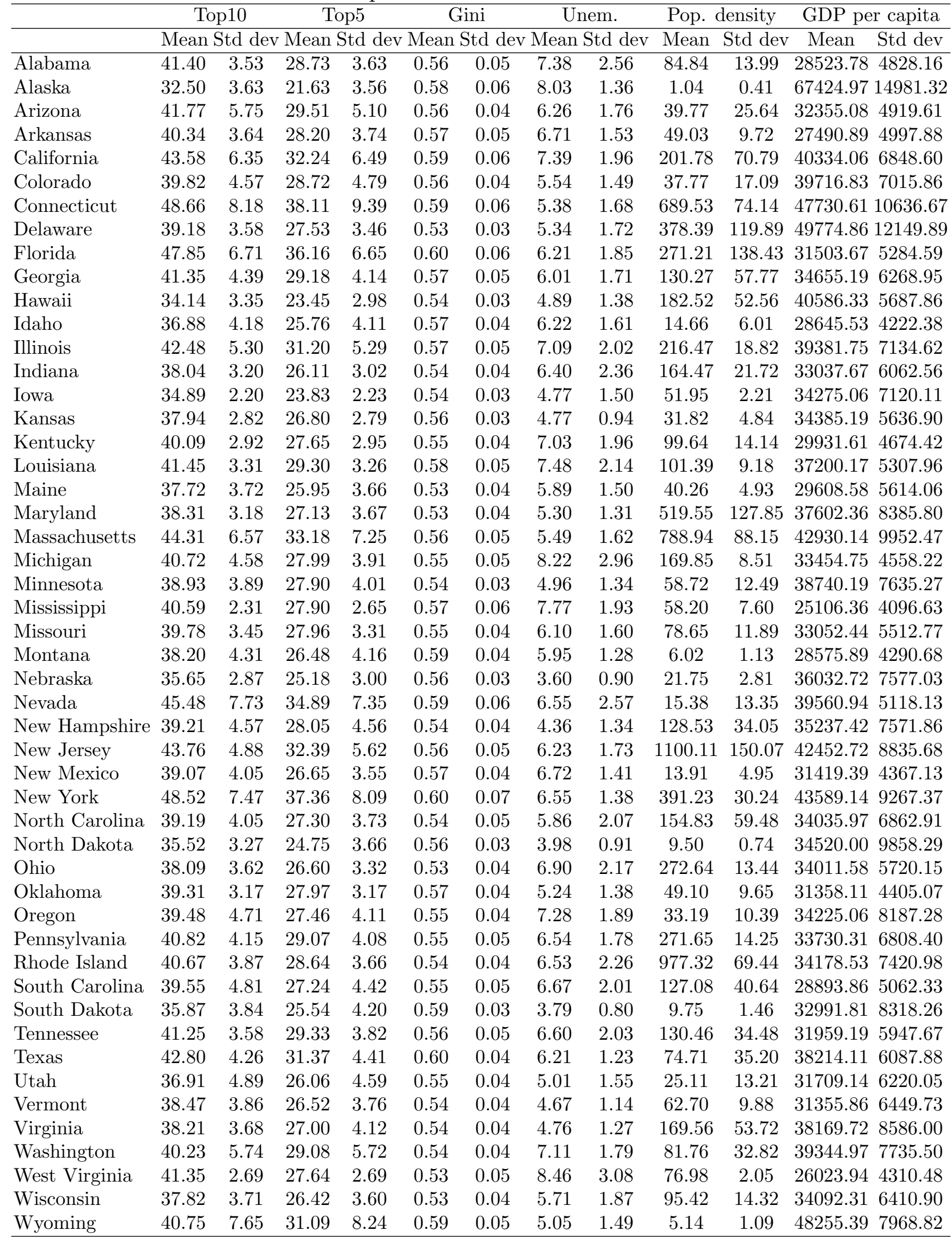


Table A3: Descriptive statistics. Deterrence data

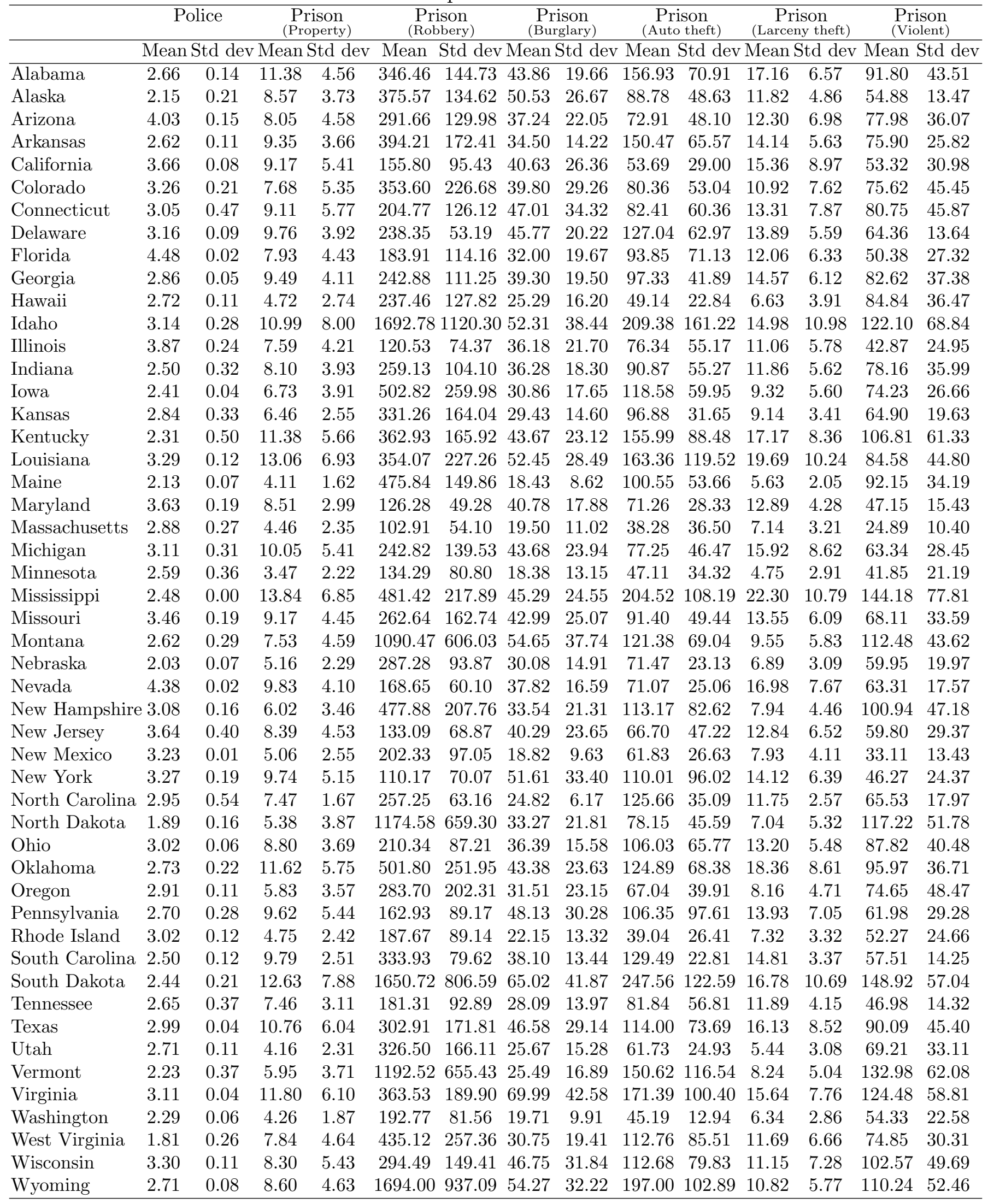




\section{Appendix C: Bai and Kao's (2006) estimator}

Bai and Kao (2006) consider the following fixed-effect panel regression:

$$
y_{i t}=\alpha_{i}+x_{i t}^{\prime} \beta+e_{i t}, i=1, \ldots, N, t=1, \ldots, T,
$$

where $\alpha_{i}$ is the intercept, $\beta$ is the slope parameter, and $e_{i t}$ is the stationary disturbance terms. $x_{i t}$ is assumed to be integrated of order one for all $i$ :

$$
x_{i t}=x_{i t-1}+\varepsilon_{i t} .
$$

To model for cross-sectional dependence, Bai and Kao (2006) assume that the error term follows a factor model

$$
e_{i t}=\lambda_{i}^{\prime} F_{t}+\mu_{i t}
$$

where $F_{t}$ is a $r \times 1$ vector of common factor a, $\lambda_{i}$ is a $r \times 1$ vector of factor loadings and $u_{i t}$ is the idiosyncratic component of $e_{i t}$, which means:

$$
E\left(e_{i t} e_{j t}\right)=\lambda_{i}^{\prime} E\left(F_{t} F_{t}^{\prime}\right) \lambda_{j},
$$

i.e. $e_{i t}$ and $e_{j t}$ are correlated due to the common factors $F_{t}$.

Bai and Kao (2006) also remark that the following factor structure could be allowed for $\varepsilon_{i t}$ (see page 5$)$

$$
\varepsilon_{i t}=\lambda_{i}^{\prime} F_{t}+\eta_{i t}
$$

Further, Bai and Kao (2006) assume that $\omega_{i t}=\left(F_{t}^{\prime}, \mu_{i t}, \varepsilon_{i t}^{\prime}\right)^{\prime}$. The long run covariance 
of $\left\{\omega_{i t}\right\}$ is given by:

$$
\begin{aligned}
\Omega & =\sum_{j=-\infty}^{\infty} E\left(\omega_{i 0} \omega_{i j}^{\prime}\right) \\
& =\Pi_{i}(1) \Sigma_{v} \Pi_{i}(1)^{\prime} \\
& =\Sigma_{i}+\Gamma_{i}+\Gamma_{i}^{\prime} \\
& =\left[\begin{array}{ccc}
\Omega_{F i} & \Omega_{F \mu i} & \Omega_{F \varepsilon i} \\
\Omega_{\mu F i} & \Omega_{\mu i} & \Omega_{\mu \varepsilon i} \\
\Omega_{\varepsilon F i} & \Omega_{\varepsilon \mu i} & \Omega_{\varepsilon i}
\end{array}\right],
\end{aligned}
$$

where

$$
\Gamma_{i}=\sum_{j=1}^{\infty} E\left(\omega_{i 0} \omega_{i j}^{\prime}\right)=\left[\begin{array}{ccc}
\Gamma_{F i} & \Gamma_{F \mu i} & \Gamma_{F \varepsilon i} \\
\Gamma_{\mu F i} & \Gamma_{\mu i} & \Gamma_{\mu \varepsilon i} \\
\Gamma_{\varepsilon F i} & \Gamma_{\varepsilon \mu i} & \Gamma_{\varepsilon i}
\end{array}\right]
$$

and

$$
\Sigma_{i}=E\left(\omega_{i 0} \omega_{i j}^{\prime}\right)=\left[\begin{array}{ccc}
\Sigma_{F i} & \Sigma_{F \mu i} & \Sigma_{F \varepsilon i} \\
\Sigma_{\mu F i} & \Sigma_{\mu i} & \Sigma_{\mu \varepsilon i} \\
\Sigma_{\varepsilon F i} & \Sigma_{\varepsilon \mu i} & \Sigma_{\varepsilon i}
\end{array}\right] .
$$

Further, Bai and Kao (2006) denote

$$
\begin{aligned}
& \Omega=\lim _{n \rightarrow \infty} \frac{1}{n} \sum_{i=1}^{n} \Omega_{i}, \\
& \Gamma=\lim _{n \rightarrow \infty} \frac{1}{n} \sum_{i=1}^{n} \Gamma_{i}, \\
& \Sigma=\lim _{n \rightarrow \infty} \frac{1}{n} \sum_{i=1}^{n} \Sigma_{i} .
\end{aligned}
$$

Given the OLS estimator of $\beta$ :

$$
\hat{\beta}_{O L S}=\left[\sum_{i=1}^{N} \sum_{t=1}^{T} y_{i t}\left(x_{i t}-\bar{x}_{i}\right)^{\prime}\right]\left[\sum_{i=1}^{N} \sum_{t=1}^{T}\left(x_{i t}-\bar{x}_{i}\right)\left(x_{i t}-\bar{x}_{i}\right)^{\prime}\right]^{-1},
$$


where $\bar{x}_{i}=\frac{1}{T} \sum_{t=1}^{T} x_{i t}$, then FM estimator of $\beta$ is constructed by correcting for endogeneity and serial correlation to the OLS estimator in (29). The endogenity correction is obtained by modifying $y_{i t}$ in $(24)$ :

$$
y_{i t}^{+}=y_{i t}-\left(\lambda_{i}^{\prime} \Omega_{F \varepsilon i}+\Omega_{\mu \varepsilon i}\right) \Omega_{\varepsilon i}^{-1} \Delta x_{i t},
$$

and the serial correlation correction term takes the form:

$$
\Delta_{b \varepsilon i}^{+}=\Delta_{b \varepsilon i}-\Omega_{b \varepsilon i} \Omega_{\varepsilon i}^{-1} \Delta_{\varepsilon i}=\left[\begin{array}{c}
\Delta_{F \varepsilon i}^{+} \\
\Delta_{\mu \varepsilon i}^{+}
\end{array}\right] .
$$

The FM estimator is then given by:

$$
\begin{array}{r}
\widetilde{\beta}_{F M}=\left[\sum_{i=1}^{N}\left(\sum_{t=1}^{T} y_{i t}^{+}\left(x_{i t}-\bar{x}_{i}\right)^{\prime}-T\left(\lambda_{i}^{\prime} \Delta_{F \varepsilon i}^{+}+\Delta_{F \varepsilon i}^{+}\right)\right)\right] \\
\\
{\left[\sum_{i=1}^{N} \sum_{t=1}^{T}\left(x_{i t}-\bar{x}_{i}\right)\left(x_{i t}-\bar{x}_{i}\right)^{\prime}\right]^{-1} .}
\end{array}
$$

In order to obtain the FM feasible estimator, $\hat{B}_{F M}, \lambda_{i}, F_{t}, \Sigma_{i}$ and $\Omega_{i}$ are replaced with $\hat{\lambda}_{i}, \hat{F}_{t}, \hat{\Sigma}_{i}$ and $\hat{\Omega}_{i}$

$$
\hat{\beta}_{F M}=\left[\sum_{i=1}^{N}\left(\sum_{t=1}^{T} y_{i t}^{+}\left(x_{i t}-\bar{x}_{i}\right)^{\prime}-T\left(\hat{\lambda}_{i}^{\prime} \hat{\Delta}_{F \varepsilon i}^{+}+\hat{\Delta}_{F \varepsilon i}^{+}\right)\right)\right]\left[\sum_{i=1}^{N} \sum_{t=1}^{T}\left(x_{i t}-\bar{x}_{i}\right)\left(x_{i t}-\bar{x}_{i}\right)^{\prime}\right]^{-1},
$$

where

$$
\hat{y}_{i t}^{+}=y_{i t}-\left(\hat{\lambda}_{i}^{\prime} \hat{\Omega}_{F \varepsilon i}+\hat{\Omega}_{\mu \varepsilon i}\right) \hat{\Omega}_{\varepsilon i}^{-1} \Delta x_{i t},
$$

and $\hat{\Delta}_{F \varepsilon i}^{+}$and $\hat{\Delta}_{\mu \varepsilon i}^{+}$are defined in same manner.

Bai and Kao (2006) assume that $\Omega_{i}=\Omega$ for all $i$. Then,

$$
\left.e_{i t}^{+}+e_{i t}-\left(\hat{\lambda}_{i}^{\prime} \hat{\Omega}_{F \varepsilon i}+\hat{\Omega}_{\mu \varepsilon i}\right) \hat{\Omega}_{\varepsilon i}^{-1} \Delta x_{i t}\right) .
$$

The CUP-FM estimator is obtained by estimating parameters, long run covariance 
matrix an loading recursively. Thus $\hat{\beta}_{F M}, \hat{\Omega}^{(1)}$ and $\hat{\lambda}_{i}^{(1)}$ are estimated repeatedly, until convergence is reached. The CUP-FM estimator is given by:

$$
\begin{aligned}
\hat{\beta}_{C U P}= & {\left[\sum_{i=1}^{n}\left(\sum_{i=1}^{T} \hat{y}_{i, t}^{+}\left(\hat{\beta}_{C U P}\right)\left(x_{i, t}-\tilde{x}_{i}\right)^{\prime}-T\left(\hat{\lambda}_{i}^{\prime}\left(\hat{\beta}_{C U P}\right) \hat{\Delta}_{F \varepsilon i}^{+}\left(\hat{\beta}_{C U P}\right)+\hat{\Delta}_{\mu \varepsilon i}^{+}\left(\hat{\beta}_{C U P}\right)\right)\right)\right] } \\
& {\left[\sum_{i=1}^{n} \sum_{t=1}^{T}\left(x_{i, t}-\bar{x}_{i}\right)\left(x_{i, t}-\bar{x}_{i}\right)^{\prime}\right]^{-1} . }
\end{aligned}
$$

